\title{
Erratum to: Comparison of the prevalence of convulsions associated with the use of cefepime and meropenem
}

\author{
Akihiro Tanaka Kenshi Takechi - Shinichi Watanabe • \\ Mamoru Tanaka · Katsuya Suemaru • \\ Hiroaki Araki
}

Published online: 7 February 2015

(C) Koninklijke Nederlandse Maatschappij ter bevordering der Pharmacie 2015

Erratum to: Int J Clin Pharm (2013) 35:683-687

DOI 10.1007/s11096-013-9799-3

In the original publication, an incorrect Table 2 (Table 1 duplicated) has been published inadvertently. The correct Table 2 is given in this erratum.

The online version of the original article can be found under doi:10.1007/s11096-013-9799-3.

\footnotetext{
A. Tanaka $(\bowtie) \cdot$ K. Takechi $\cdot$ S. Watanabe $\cdot$ M. Tanaka .

H. Araki

Division of Pharmacy, Ehime University Hospital,

454 Shitsukawa, Toon, Ehime 791-0295, Japan

e-mail: akiki@m.ehime-u.ac.jp

K. Suemaru

School of Pharmacy, Shujitu University, 1-6-1 Nishigawara,

Okayama 703-8516, Japan
} 
Table 2 Clinical characteristics of patients with meropenem-associated convulsions

\begin{tabular}{|c|c|c|c|c|c|c|c|}
\hline No. & $\begin{array}{l}\text { Patient } \\
\text { characteristics } \\
\text { (sex, age, } \\
\text { eGFR) }\end{array}$ & $\begin{array}{l}\text { Daily } \\
\text { dosing } \\
\text { schedule }\end{array}$ & $\begin{array}{l}\text { Time of } \\
\text { symptoms } \\
\text { (days from } \\
\text { start of } \\
\text { cefepime) }\end{array}$ & $\begin{array}{l}\text { Symptoms and } \\
\text { signs }\end{array}$ & $\begin{array}{l}\text { Baseline } \\
\text { disease }\end{array}$ & $\begin{array}{l}\text { Anticonvulsant } \\
\text { agent }\end{array}$ & Final assessment \\
\hline A & $\begin{array}{l}\mathrm{F}, 42, \\
95 \mathrm{~mL} / \mathrm{min}\end{array}$ & $\begin{array}{l}0.5 \mathrm{~g} \\
\text { every } \\
8 \mathrm{~h}\end{array}$ & 2 & Clonic convulsion & $\begin{array}{l}\text { Cerebral } \\
\text { infarction }\end{array}$ & $\begin{array}{l}\text { Phenytoin (iv), } \\
\text { valproic acid } \\
\text { (po) }\end{array}$ & $\begin{array}{l}\text { Administer thiamylal, and then } \\
\text { complete resolution }\end{array}$ \\
\hline B & $\begin{array}{l}\mathrm{M}, 59, \\
106 \mathrm{~mL} / \mathrm{min}\end{array}$ & $\begin{array}{l}0.5 \mathrm{~g} \\
\text { every } \\
8 \mathrm{~h}\end{array}$ & 2 & Clonic convulsion & Encephaloma & None & $\begin{array}{l}\text { Administer diazepam intravenously, } \\
\text { and then complete resolution }\end{array}$ \\
\hline $\mathrm{C}$ & $\begin{array}{l}\mathrm{F}, 74, \\
69 \mathrm{~mL} / \mathrm{min}\end{array}$ & $\begin{array}{l}1 \mathrm{~g} \\
\text { every } \\
12 \mathrm{~h}\end{array}$ & 2 & Myoclonus & $\begin{array}{l}\text { Multiple } \\
\text { cerebral } \\
\text { infarction }\end{array}$ & $\begin{array}{l}\text { Clonazepam } \\
\text { (po) }\end{array}$ & $\begin{array}{l}\text { Administer diazepam intravenously, } \\
\text { but uncontrollable convulsion, and } \\
\text { then complete resolution }\end{array}$ \\
\hline D & $\begin{array}{l}\mathrm{F}, 39, \\
76 \mathrm{~mL} / \mathrm{min}\end{array}$ & $\begin{array}{l}1 \mathrm{~g} \\
\text { every } \\
12 \mathrm{~h}\end{array}$ & 2 & $\begin{array}{l}\text { Clonic convulsion } \\
\text { and decreased } \\
\text { level of } \\
\text { consciousness }\end{array}$ & $\begin{array}{l}\text { B- cell } \\
\text { lymphoma } \\
\text { (infiltration } \\
\text { brain), } \\
\text { febrile } \\
\text { neutropenia }\end{array}$ & $\begin{array}{l}\text { Zonisamide } \\
\text { (po) }\end{array}$ & $\begin{array}{l}\text { Administer diazepam intravenously, } \\
\text { and then complete resolution after } \\
\text { the discontinuation of meropenem }\end{array}$ \\
\hline
\end{tabular}

